\title{
PEDAGOGICAL MODELS FOR COMPELLING LEARNING EXPERIENCES WITH TECHNOLOGY
}

\author{
Patrick Parrish, World Meteorological Organization, Switzerland
}

\begin{abstract}
Technology offers tremendous opportunities to improve learning experiences and outcomes. However, we should be striving for technology-enhanced learning that not only brings more to learners, but demands more of them as well. Learning experiences that strive for significant impacts should challenge learners to solve problems, conduct investigations, strategize courses of action, or construct knowledge through personal projects. Such experiences can bring out the aesthetic potential of learning, leading to transformative outcomes. This paper argues for the importance of considering this aesthetic potential to make learning compelling, and describes four instructional projects developed in my own work in recent years. These projects used four different, well-researched pedagogical models as the basis for their approaches.
\end{abstract}

Keywords: Technology-enhance learning, learning strategies, learning experience, aesthetics, instructional design, case-based learning, inquiry-based learning, game-based learning, project-based learning

\section{Aesthetics and Learning}

Educational technologies have slowly, and often rapidly, changed the learning landscape in the last 40 years. Today, learning opportunities include information on demand, digital multimedia demonstrations and explanations, self-directed smart tutorials and simulations, and telecommunications via the internet that connect learners to distant teachers, colleagues, coaches and mentors. Artificial intelligence promises to personalize learning experiences as never before.

But some things do not change with the changing technology. Learning still occurs more deeply and leads to more transformative outcomes when learners are required to give more of them themselves to the effort. Ideally, we should be striving for technology-enhanced learning experiences that not only bring more to learners, but demand more of them as well. Learning experiences that strive for significant impacts should challenge learners to 
Parrish, $P$.

Pedagogical Models for Compelling Learning Experiences with Technology

solve problems, conduct investigations, strategize courses of action, or construct knowledge through personal projects.

This perspective might be distilled to the long-held principle of "learning by doing", but this does not capture the rewarding feelings of transformation possible (and often sheer joy) that make learning a compelling activity. A more complete description are the words, "aesthetic experience". In general terms, aesthetic learning experiences are compelling, immersive, demanding, and lead to intrinsic rewards of accomplishment. They achieve this by presenting challenges that encourage high levels of engagement and demand resolution, or consummation. This concept of aesthetics relates to Pragmatist (Dewey, 1934/1989) and other aesthetic theories that broaden the concept beyond the fine arts to experiences of everyday life, which helps to solve the puzzle of the existence and universal rewards of the arts in all cultures, as well as the many activities that have been classified as arts throughout history (including, among others, physical skills, ceremonies and warfare) and the explosion of new art forms in the post-modern period into performance art, environmental art, and installations.

I and others have argued in recent years that there are inherent aesthetic qualities to effective learning experiences, not unlike those experienced in appreciating great works of visual, musical, literary, environmental and narrative arts (Parrish, 2005; Parrish, 2009; Parrish, Wilson, \& Dunlap, 2011). Moreover, we have argued for the importance of attending to these qualities of learning by teachers and designers of learning experiences. Experiences, by nature, are transactional (Parrish, Wilson, \& Dunlap, 2011). In other words, both the situation and the individuals involved have critical roles in the developmental potential of the experience. The situation, in the case of teaching, can be more or less immediate, malleable, compelling, resonant, and coherent. The individuals involved can be more or less intent, present, open, and trusting. Both are critical to the nature of the experience, both equally responsible. Pedagogical models that emphasize these elements in the situation, but also demand them from the individuals involved, are likely to be the most successful.

The performative qualities of learning and teaching, like other performances we engage in for inherent rewards (i.e., not necessarily performance as entertainment), can be best described as aesthetic (Shusterman, 2000). The narrative arc that describes how we engage with works of art, in other words, how art does its work, also describes learning. In both cases, we enter a problematic situation that demands attention and resolution, confront challenges and increasing levels of complexity, and to varying degrees, achieve a resolution, or denouement, that unifies the experience. This is most obvious in narrative works of art, but also in other experiences, like walking through an interesting work of architecture or listening to a driving musical composition. Even more fundamentally, this 
Parrish, $P$.

Pedagogical Models for Compelling Learning Experiences with Technology

arc comprises any act involved in being an effective agent in understanding and influencing our environments--which include the intellectual capabilities we contribute, along with external, physical qualities and other actors within the ecosystems in which we live. The narrative arc is an important and fundamental element of life, and not just art (Dewey, 1934/1989). It drives us to our achievements and encourages us to strive for more.

In previous papers, I have explored the aesthetic dimensions of learning and teaching, and defined aesthetic principles for instructional design (Parrish, 2009). In this paper, I intend to further this work by describing several general instructional strategies, often known as learning methods, that I believe encourage aesthetic learning experiences. These will be exemplified in my own work during the last 15 years as a designer of instruction and manager at a not-for-profit science education organization, the COMET Programme, in Boulder, Colorado, USA, and as a manager of training activities in an specialized agency of the United Nations, the World Meteorological Organization.

These strategies include case-based, inquiry-based, game-based, and project-based learning. Each of these have been the subject of significant research into learning and instructional design theory. They have mostly been studied in terms of their cognitive foundations, while I am concerned here primarily with their aesthetic affordances. These two viewpoints are not in conflict, but complimentary. In the broadest sense of aesthetics, all human activities, including intellectual ones, have aesthetic potential due to the challenge, engagement and rewards they can bring.

\section{Case-based Learning: Polar Lows Ungava Bay 01 December 2000}

Cases have been argued as one of the basic ways we store knowledge for making decisions (Kolodner \& Guzdial, 2000; Schank et al., 1999). We recall experienced or learned cases to provide guidance for taking action whenever we encounter problematic situations. Research has shown that professionals that are required to make critical decisions rapidly, like fire fighters, use their repertoire of cases to guide them in new situations.

The case-based, self-directed learning module titled Polar Lows: Ungava Bay, was developed by the COMET Program in 2004 for weather forecasters who face critical decision making during the rapidly evolving phenomenon in high latitudes known as "polar lows," which move toward lower latitudes over cold waters, bringing severe winds, rains and snow. Ungava Bay, where this case takes place, is in the far north of Canada. (The module can be found at COMET MetEd website (2004). Note that the use of Flash programming can limit usability in some browsers.)

Nearly any case-based learning design can be highly engaging due to the natural narrative in the unfolding of the case. The particular design of Polar Lows places additional demands 
Parrish, $P$.

Pedagogical Models for Compelling Learning Experiences with Technology

on the learner due to its learning object-oriented design that first asks the learner to make diagnostic and then prognostic decisions based on data products provided, such as satellite imagery and atmospheric temperature and moisture soundings, and only then recommends the learning object resources that provide background knowledge for guiding those decisions. The learning objects use text, narration, and animation to describe information such as the formation mechanisms of polar lows and atmospheric conditions that drive the evolution and movement of the system. In other words, the case uses the reverse of the traditional explain-how-and-then-practice approach. The case is composed of a Case Overview that sets the background context, a Case Challenge that requires 8 different decisions, and only finally a Case Summary, which offers a traditional explanatory lecture regarding the case.

During the Case Challenge, a learner is allowed to study the provided weather data products, which incrementally changes through the temporal sequence of the event, to make initial decision attempts before refining the decision based on expert guidance. The learner can study the recommended learning objects and make the initial diagnostic and prognostic decisions whenever she feels ready, and then receive detailed feedback on their likely correctness before deciding if additional study would be helpful before moving on to the next decision. The chosen case is a complex one, with built-in, non-intuitive complexities, introducing a few surprises and requiring creative thinking. The final Case Summary provides a logically flowing descriptive analysis of the case to ensure that the learner takes away the key lessons offered by the case.

This online module won a 2004 Brandon-Hall Excellence in Learning Gold Medal Award in the Custom Content category, which highlights exceptional work in the field of online learning. Learners that used it were likely at first surprised by its unconventional format of just-in-time information rather than a more guided learning approach. Statistics show that Polar Lows has been used in nearly 500 online sessions, which is not an exceptional number of uses for modules developed by the COMET Program. (Online sessions correlate to completions, but does not exactly indicate completion). However, one additional casebased learning module was designed using the same object-oriented, learner-driven approach, "Ocean Effect Snow: New England Snow Storm, 14 January 1999". It has been used in over 850 sessions. The phenomenon that drives the case, due to its higher occurrence among the learner audience, likely led to increased popularity.

\section{Inquiry-based Learning: Tsunami Strike! Caribbean Edition}

Inquiry-based learning essentially asks learners to behave like researchers, to learn the way researchers methodically investigate a body of knowledge or evidence to come to conclusions. Instructors that use this strategy might pose questions, problems, or 
Parrish, $P$.

Pedagogical Models for Compelling Learning Experiences with Technology

hypotheses, or tell stories of problematic situations that will naturally engage students' curiosity. They then ask learners to follow a process of inquiry to resolve the indeterminate situation created. Problem-based learning is a popular form of inquiry-based learning (Hmelo-Soéver, 2004; Savery \& Duffy, 1996).

In a way, inquiry forms the basis of all useful learning, which begins with a question or an experience that requires an answer or resolution. The skills required for an effective inquiry are needed in every profession. All professionals need to be able to solve the problems that they encounter and seek information to make decisions. Inquiry requires more than remembering facts, concepts, and principles, it also requires higher-level thinking skills such as critical and creative thinking, analysis and judgment, as well as problem solving and decision making. Inquiry also generates motivation by establishing a natural drama based on seeking the answer to a question or resolving a puzzling phenomenon. When brought to the fore of a learning experience, inquiry changes the tone of instruction from passive reception to intentional action.

Tsunami Strike! Caribbean Edition (COMET MetEd, 2017), developed by my team within the COMET Program and published in 2012, using HTML and Flash-based programming, is designed for middle and high-school learners, who are asked to take on the role of a journalist writing an article for a news magazine on the potential occurrence and impacts of tsunamis in their home island countries. Sixteen multimedia lessons (learning objects) on tsunami science, geography, safety, and history are interwoven as resources the students can use as background for producing the article. The material is aimed at students ages 13-17, helps students to learn about tsunami risks in the Caribbean region due to ocean-based seismic and other events, which contributes to curricula in physics, earth sciences, geography, and social science. Reviews and feedback on the articles produced by students requires work by dedicated teachers--this is not a fully self-directed learning experience like Polar Lows.

Tsunami Strike! Caribbean Edition, at one point, became one of the most highly used COMET Program modules, reaching 2750 user sessions. The space to contribute to the experience given to teachers who employ the module in their courses may increase their desire to use it within their curricula. A closed, self-directed module might not have the same impact. In effect, an open educational resource that requires local adaption and inquiry-based learning by students creates an aesthetic opportunity for both teachers and learners. 
Parrish, $P$.

Pedagogical Models for Compelling Learning Experiences with Technology

\section{Game-based Learning: Learnopoly}

Game-based learning is not grounded in a single learning theory, but much research has been conducted on the effectiveness of using games and gamification to engage learners to reach higher levels of engagement and develop complex cognitive skills (Gee, 2013; Myers \& Reigeluth, 2017).

Games are universally used to provide challenging environments for intellectual stimulation and/or physical exercise (Callois, 2001). They also serve a social function, but perhaps foremost, they create a goal and competitive environment to stimulate and heighten performance. Their use in education has probably always existed, but in response to the immense popularity of computer video games, the potential to motivate students increased interested in game-based learning during the last three decades. In a way, games offer a practice field for life skills, both social and cognitive, and the interest of educators in using games as a serious component for learning has rapidly grown with the support of technology. Games offer a safe but motivating environment for practice.

One of James Paul Gee's sixteen principles of good game based learning is "Performance before Competence" (Gee, 2013), the proposal that people should be able to gain competence through taking action, and not just practice performance after gaining competence. This principle is in concert with the preceding designs described in this paper.

Learnopoly is a game designed for exercising skills of instructional design for active learning approaches, where competing teams of players race to design learning activities for randomly assigned topics in their professional field of meteorology, for online or classroom use. The design constraints are determined by randomly choosing cards and spinning a wheel. Cards decide the type of learning activity that must be designed (discussion, case study, project, simulation or role play, practice exercises, collaborative decision making, Socratic lesson, etc. ), and the spin decides the delivery mode--whether the activity will be carried out synchronously online, asynchronously online, or in a classroom. The goal of the game is to offer a creative challenge to trainers to use different learning activities for different delivery modes in effective and engaging ways. The game offers a safe and entertaining environment where players are forced to challenge themselves to come up solutions they might not otherwise do in the current work environments. The game was designed by Maja Kuna-Parrish and myself for use in two training workshops, one in a face-to-face environment using physical cards and spinners, and one delivered online, using software to randomize the selections and small group discussion forums for team communications.

The goal of the game was for teams to develop as many valid, brief learning design descriptions as possible within the time constraints, competing with the other teams to 
Parrish, $P$.

Pedagogical Models for Compelling Learning Experiences with Technology

develop the most and best judged designs. Decisions on "best" designs were voted on by all teams at the end of the session, after each team nominated one of their activities and described it to the other teams.

Slides depicting the game play, used to introduce the game online (Kuna, 2014). Learnopoly was first introduced as a workshop activity at the 2014 Eumetcal Workshop held in Warsaw, Poland, from 10 to 13 June. Over 30 players tried out the game, successfully came up with a large set of solutions, and provided useful feedback for game improvements. A similar number of participants joined the online version on year later. Feedback in evaluations showed that the participants appreciated the game characteristics (fast pace, randomly assigned content and delivery choices, time constraints, and competition) as well as the small group brainstorming, discussion and decision making. Some respondents were uncomfortable with the game logistics and creative, fast-paced group work, so more coaching would probably have helped.

\section{Project-based Learning: WMO Courses for Trainers}

Project-based learning strategies are, in a broad sense, also Inquiry Strategies, efforts to resolve an indeterminate situation by applying new and existing knowledge in constructing solutions. They are also Constructionist strategies (Papert \& Harel, 1991), which promote learning through the process of producing tangible, sharable outputs. In project-based learning, students work individually or in small groups to produce products such as a report, plan, poster, presentation, digital media, or model (conceptual or physical). Through projects, students are exposed to new information, develop new mental models and practice skills in the process of completing the project-in other words, in a relevant rather than artificial context.

Project-based learning tasks have many peripheral outcomes as well, such as developing interpersonal skills, commitment and independence. They are inherently motivating due to their aesthetic arc, with beginnings, middles and ends, filled with incremental challenges, like a good story.

The WMO Online Course for Trainers has been offered at least once annually since 2014, with the goal of developing trainer competencies in regional and national training institutions. It teaches knowledge and skills required to make informed instructional planning decisions, through a process that requires instructional design thinking. So far, it has been offered in 4 languages to a global audience, and has seen over 450 participants achieve successful completion. Because the course requirements include the development of a comprehensive Training Development Plan, the project of the course, requiring detailed documentation of each step of the planning process, this number of successful completions is somewhat remarkable. 
Parrish, $P$.

Pedagogical Models for Compelling Learning Experiences with Technology

Training Development Plan (TDP), based on a template provided at the start of the course is the glue that ties the course together, although many other activities are conducted during the course through the Moodle virtual learning environment in which it is based. In addition, the TDP is immediately relevant to participant work responsibilities. While many participants have never planned training using the systematic method taught, all will have had to make similar training decisions.

For the TDP, participants are asked to choose a training project for which they are currently responsible, or one they need to accomplish in the near future. The final product could potentially be valuable for participants' work, leading to a new or improved course design.

The TDP is developed incrementally starting during the first week, based on content and skills learned in each unit. Feedback is also provided incrementally by a number of Coaches, at three to four points during the course, allowing improvements throughout. The sections of the plan correspond directly to the competencies being taught. The TDP scope and length make this a major assignment - often 10 to 20 pages long - which is significant for a professional development course taught outside a university. However, the incremental production and feedback makes it doable and rewarding for nearly all participants.

Feedback on the course is nearly universally positive, and often glowing, with testimonies that the concepts and techniques taught are revelatory. In reality, I would argue that it is not the course content, but the compelling process of producing the TDP that leads to such positive responses.

\section{The importance of compelling experiences}

This paper has described four designs for learning experiences that relied upon technology, but were grounded in proven learning strategies that demand the deep engagement of learners. They were discussed as effective not because they offered easy access to welldesigned information, but because they required learners to construct knowledge during creative processes of problem solving, decision making, and production of products. These activities are at the highest levels of cognitive engagement, but can also reach the dimensions of aesthetic engagement. I would argue that aesthetic engagement should be a goal of instruction when our goals are transformative learning and high degrees of personal development, if not always. Learning experiences that are compelling lead to learning that stays in the minds and actions of learners and primes them to become lifelong learners. During such experiences, action is the source of learning--a personal, intentional action-and not simply an attempt to give and receive knowledge. This is certainly not a new argument, but one that demands repeating in a stubborn culture that continues to view 
Parrish, $P$.

Pedagogical Models for Compelling Learning Experiences with Technology

learning as a thing transferred from expert to student rather than something freshly constructed by each learner.

\section{References}

Callois, R. (2001). Man, Play and Games. Urbana: University of Illinois.

COMET MetEd. (2004). Polar Lows Ungava Bay 01 December 2000. Retrieved from https://www.meted.ucar.edu/training_module.php?id=144

COMET MetEd. (2017). Tsunami Strike! Caribbean Edition. Retrieved from https://www.meted.ucar.edu/training_module.php?id=907

Dewey, J. (1934/1989). Art as experience (Vol. 10). Carbondale: Southern Illinois University.

Gee, J. P. (2013). Good Video Games and Good Learning: Collected Essays on Video Games, Learning and Literacy ( $2^{\text {nd }}$ ed.). Bern: Peter Lang Inc., International Academic Publishers.

Hmelo-Silver, C. E. (2004) Problem-based Learning: What and How Do Students Learn? Educational Psychology Review, 16(3).

Kolodner, J. L., \& Gusdial, M. (2000) Theory and practice of case-based learning aids. In D. H. Jonassen \& S. M. Land (Eds.), Theoretical foundations of learning environments (pp. 215-242). Mahwah, NJ: Lawrence Erlbaum Associates.

Kuna (2014). Learnopoly - the game of learning activities. Retrieved from https://www.slideshare.net/slideshow/embed_code/37168679

Myers, R. D. \& Reigeluth, C. M. (2017) Designing games for learning. In C. M. Reigeluth, Myers, R. D. \& Beatty, B. J. (Eds.), Instructional -design theories and models, Volume IV: The learner-centered paradigm of education (pp. 205-242). Mahwah, NJ.: Lawrence Earlbaum Associates.

Papert, S. \& and Harel, I. (1991). Constructionism. New York: Ablex Publishing Corporation.

Parrish, P. E. (2005). Embracing the aesthetics of instructional design. Educational Technology, 45(2), 16-25.

Parrish, P. E. (2009). Aesthetic principles for instructional design. Educational Technology Research and Development, 57(4), 511-528.

Parrish, P. E., Wilson, B. G. \& Dunlap, J. C. (2011). Learning experience as transaction: A framework for instructional design. Educational Technology, 51(2), 15-22. 
Savery, J. R., \& Duffy, T. M. (1996). Problem based learning: An instructional model and its constructivist framework. In B. G. Wilson (Ed.), Constructivist learning environments (pp. 135-148), Englewood Cliffs, NJ: Educational Technology Publications.

Schank, R. C., Berman, T. R., \& Machpherson, K. A. (1999). Learning by doing. In C. M. Reigeluth (Ed.), Instructional design theories and models, Volume II: A new paradigm of instructional theory (pp. 161-181). Mahwah, NJ.: Lawrence Earlbaum Associates.

Shusterman, R. (2000). Performing live: Aesthetic alternatives for the ends of art. Ithaca: Cornel University. 